\title{
Skeletal muscle insulin resistance is induced by 4-hydroxy-2-hexenal, a by-product of $n-3$ fatty acid peroxidation
}

\author{
Christophe O. Soulage ${ }^{1}$ - Laura Sardón Puig ${ }^{2}$ - Laurent Soulère ${ }^{3} \cdot$ Bader Zarrouki $^{4}$ - Michel Guichardant ${ }^{1}$. \\ Michel Lagarde ${ }^{1} \cdot$ Nicolas J. Pillon ${ }^{5}$
}

Received: 17 August 2017 / Accepted: 17 November 2017 / Published online: 3 January 2018

(C) The Author(s) 2018. This article is an open access publication

\begin{abstract}
Aims/hypothesis Oxidative stress is involved in the pathophysiology of insulin resistance and its progression towards type 2 diabetes. The peroxidation of $n$-3 polyunsaturated fatty acids produces 4-hydroxy-2-hexenal (4-HHE), a lipid aldehyde with potent electrophilic properties able to interfere with many pathophysiological processes. The aim of the present study was to investigate the role of 4-HHE in the development of insulin resistance.

Methods 4-HHE concentration was measured in plasma from humans and rats by GC-MS. Insulin resistance was estimated in healthy rats after administration of 4-HHE using hyperinsulinaemic-euglycaemic clamps. In muscle cells, glucose uptake was measured using 2-deoxy-D-glucose and signalling pathways were investigated by western blotting. Intracellular glutathione was measured using a fluorimetric assay kit and boosted using 1,2-dithiole-3-thione (D3T).

Results Circulating levels of 4-HHE in type 2 diabetic humans and a rat model of diabetes (obese Zucker diabetic fatty rats), were twice those in their non-diabetic counterparts (33 vs $14 \mathrm{nmol} / 1, p<0.001$ ), and positively correlated with blood glucose levels. During hyperinsulinaemic-euglycaemic clamps in rats, acute intravenous injection of 4HHE significantly altered whole-body insulin sensitivity and decreased glucose infusion rate $(24.2$ vs $\left.9.9 \mathrm{mg} \mathrm{kg}^{-1} \mathrm{~min}^{-1}, p<0.001\right)$. In vitro, 4-HHE impaired insulin-stimulated glucose uptake and signalling (protein kinase B/Akt and IRS1) in L6 muscle cells. Insulin-induced glucose uptake was reduced from 186 to $141.9 \mathrm{pmol} \mathrm{mg}^{-1} \mathrm{~min}^{-1}(p<0.05)$. 4-HHE induced carbonylation of cell proteins and reduced glutathione concentration from 6.3 to $4.5 \mathrm{nmol} / \mathrm{mg}$ protein. Increasing intracellular glutathione pools using D3T prevented 4-HHE-induced carbonyl stress and insulin resistance.

Conclusions/interpretation 4-HHE is produced in type 2 diabetic humans and Zucker diabetic fatty rats and blunts insulin action in skeletal muscle. 4-HHE therefore plays a causal role in the pathophysiology of type 2 diabetes and might constitute a potential therapeutic target to taper oxidative stress-induced insulin resistance.
\end{abstract}

Nicolas J. Pillon

nicolas.pillon@ki.se

1 Univ Lyon, CarMeN, INSA-Lyon, Inserm UMR 1060, INRA UMR 1397, Université Claude Bernard Lyon 1, Villeurbanne, France

2 Department of Molecular Medicine and Surgery, Karolinska Institutet, Stockholm, Sweden

3 Univ Lyon, INSA-Lyon, CPE Lyon, Université de Lyon 1, UMR 5246, CNRS, ICBMS, Institut de Chimie et de Biochimie Moléculaires et Supramoléculaires, Chimie Organique et Bioorganique (COB), Villeurbanne, France

Keywords 4-HHE - Insulin resistance - Lipid aldehyde · Peroxidation $\cdot$ Skeletal muscle

Bioscience Diabetes, Cardiovascular and Metabolic Diseases, IMED Biotech Unit, AstraZeneca, Gothenburg, Sweden

5 Department of Physiology and Pharmacology, Karolinska Institutet, von Eulers väg 4a, IV, SE-171 77 Stockholm, Sweden

$\begin{array}{ll}\text { Abbreviations } \\ \text { DHA } & \text { Docosahexaenoic acid } \\ \text { D3T } & \text { 1,2-Dithiole-3-thione } \\ \text { DNPH } & \text { 2,4-Dinitrophenylhydrazine } \\ \text { EIA } & \text { Enzyme immunoassay } \\ \text { GSH } & \text { Reduced glutathione } \\ \text { 4-HHE } & \text { 4-Hydroxy-2-hexenal } \\ \text { 4-HNE } & \text { 4-Hydroxy-2-nonenal } \\ \text { LDH } & \text { Lactate dehydrogenase } \\ \text { MTT } & \text { 3-(4,5-Dimethylthiazol-2-yl)-2, } \\ & \text { 5-diphenyltetrazolium bromide } \\ \text { PKB } & \text { Protein kinase B } \\ \text { PUFA } & \text { Polyunsaturated fatty acids } \\ \text { ZDF } & \text { Zucker diabetic fatty }\end{array}$




\section{Research in context}

\section{What is already known about this subject?}

- Oxidative stress is involved in the development of insulin resistance

- The concentration of various lipid peroxidation by-products is increased in type 2 diabetic individuals

- 4-Hydroxy-2-hexenal (4-HHE) is produced by the specific peroxidation of $n-3$ fatty acids

\section{What is the key question?}

- Can 4-HHE play a causal role in the development of insulin resistance?

\section{What are the new findings?}

- The concentration of 4-HHE is increased in the plasma of type 2 diabetic humans and a rat model of diabetes and correlated with $\mathrm{HbA}_{1 \mathrm{c}}$ and blood glucose levels

- Infusion of 4-HHE in vivo triggers skeletal muscle insulin resistance

- Antioxidant strategies can prevent the deleterious effects of 4-HHE on skeletal muscle insulin sensitivity

\section{How might this impact on clinical practice in the foreseeable future?}

- Prevention of formation of lipid peroxidation by-products in individuals with type 2 diabetes might help improve whole body insulin sensitivity

\section{Introduction}

Oxidative stress is involved in the pathophysiology of many chronic diseases and in particular contributes to the development of insulin resistance and its progression towards type 2 diabetes [1-3]. Peroxidation of cell membrane phospholipids associated with oxidative stress produces deleterious reactive species. Peroxidation of $n-6$ polyunsaturated fatty acids (PUFA) leads to the production of 4-hydroxy-2-nonenal (4HNE), while 4-hydroxy-2-hexenal (4-HHE) is released during the oxidation of $n$-3-PUFA [4]. These lipid aldehydes are major by-products of lipid peroxidation of PUFA and exhibit potent electrophilic properties allowing them to form covalent adducts with phospholipids, proteins and nucleotides $[5,6]$. Because of their relative stability and high reactivity, these aldehydes are thought to interfere with crucial physiological processes such as cell cycle, apoptosis or metabolic pathways [7-9]. Importantly, the production of 4-hydroxyalkenals is associated with hindered insulin responses: 4-HNE-adducts accumulate in liver and pancreatic beta cells of diabetic rats [10-12], impairs glucose-induced insulin secretion in isolated beta cells [13] and blunts insulin action in 3T3-L1 adipocytes and L6 muscle cells $[14,15]$.

Increased consumption of $n$-3 PUFA might be expected to produce beneficial effects [16]; however, enhanced 4-HHE formation in conditions associated with oxidative stress might be harmful. For instance, consumption of oxidised $n-3$ PUFA induces oxidative stress and inflammation of mice intestine [17]. 4-HHE has, however, received little attention, despite its similarities in structure and its reactivity with related aldehydes. Indeed, 4-HHE is also produced under oxidative stress conditions, accumulates in tissues $[18,19]$ and is able to form adducts on biological molecules [20,21]. Only a handful of studies have shown activation of stress signalling pathways by 4-HHE [22, 23] but data regarding its pathophysiological effects remains scarce. Especially, the putative role of 4-HHE in the development of insulin resistance has not been investigated. In the present study we hypothesised that circulating levels of 4-HHE are elevated in diabetic individuals and that 4-HHE can impair insulin responses in skeletal muscle cells and contribute to insulin resistance in vivo.

\section{Methods}

Reagents 4-HNE and 4-HHE were synthesised as previously described [24]. Insulin (Actrapid, $100 \mathrm{U} / \mathrm{ml}$ ) was from Novo Nordisk (La Défense, France) and ECL reagent and 2-deoxyD-2,6- $\left[{ }^{3} \mathrm{H}\right]$ glucose were from GE Healthcare (Orsay, France). 1,2-Dithiole-3-thione (D3T) was from Interchim (Montlucon, France). All other reagents were from Sigma-Aldrich (Saint Quentin Fallavier, France).

Antibodies Antibodies to Ser473-Akt, total Akt, p85 and total IRS1 (dilution 1:1000) were from Cell Signaling (Leiden, the Netherlands). Secondary antibodies (dilution 1:10,000) were from Sigma-Aldrich (Heidelberg, Germany). Anti-HHEMichael adducts antibodies were from Cosmobio (Tokyo, 
Japan). Antibodies for insulin signalling were validated using insulin as a positive control. Anti-HHE antibody specificity was tested against protein lysates incubated with 4-HHE or 4HNE.

Participants Fifteen individuals with type 2 diabetes mellitus and 17 healthy volunteers were recruited from an ongoing study at Hospices Civils de Lyon. The characteristics of the participants are shown in Table 1. The study was approved by the local ethics committee (reference D-09-17) and written informed consent was obtained from all volunteers. After an overnight fast, blood samples were collected, centrifuged at $1500 \mathrm{~g}$ for $10 \mathrm{~min}$ to isolate plasma and stored at $-80^{\circ} \mathrm{C}$.

Animal experiments All animal experiments were performed under authorisation no. 69-266-0501 (INSA-Lyon, DDPP-SV, Direction Départementale de la Protection des Populations Services Vétérinaires du Rhône) according to the guidelines laid down by the French Ministry of Agriculture (no. 2013118 ) and the European Union Council Directive for the protection of animals (2010/63UE).

The rats used in all experiments were raised in an airconditioned room with a controlled environment of $21 \pm$ $0.5^{\circ} \mathrm{C}$ and $60-70 \%$ humidity, under a $12 \mathrm{~h}$ light-dark cycle (light on from 07:00 to 19:00 hours) with free access to food (2016C, 12.6 kJ/g; Harlan, Gannat, France) and water. Rats were housed together and randomised into groups on the day of the experiment using random numbers.

Zucker diabetic fatty rats Five-week-old male lean (ZDFLepr $^{\mathrm{fa}} /+/$ ?,$n=5$ ) and obese Zucker diabetic fatty (ZDF) rats (ZDF-Lepr ${ }^{\mathrm{fa}} / \mathrm{Crl}, n=5$ ), a rat model of diabetes, were purchased from Charles River Laboratories (L'Arbresle, France). The characteristics of the rats are shown in Table 2. At 15 weeks of age, rats were deeply anaesthetised with sodium pentobarbital (120 mg/kg i.p.). Terminal cardiac blood puncture was collected into a heparinised syringe and blood was centrifuged for $2 \mathrm{~min}$ at $3500 \mathrm{~g}$ to prepare plasma, snapfrozen in liquid nitrogen and stored at $-80^{\circ} \mathrm{C}$. Blood glucose was measured with a glucometer (Accu-Check Performa; Roche, Meylan, France) and insulin was determined using an enzyme immunoassay (EIA) according to the manufacturer's recommendations (A05005; Bertin Pharma, Montigny le Bretonneux, France). $\mathrm{HbA}_{1 \mathrm{c}}$ was determined on whole blood using a rat glycated haemoglobin assay kit (80300; Crystal Chem, Zaandam, the Netherlands).

Euglycaemic-hyperinsulinaemic clamps Clamps were performed in 3-month-old anaesthetised male Wistar rats [25] purchased from Janvier (Le-Genest-Saint-Isle, France). Rats were fasted overnight, anaesthetised with sodium pentobarbital (35 mg/kg i.p.; Sanofi Santé Animale, Centravet, Lapalisse, France) and chlorpromazine
(5 mg/kg, i.p., Largactil; Sanofi-Aventis, Paris, France) and then implanted with indwelling catheters (PE-20; Phymep, Paris, France) in the left carotid artery and left and right jugular veins. After catheterisation, four rats were infused with 4-HHE $(10 \mathrm{mg} / \mathrm{kg}, 0.1 \mathrm{ml})$ and four rats were infused with the vehicle (DMSO, $0.1 \mathrm{ml}$ ) in the left jugular vein. A standard $2 \mathrm{~h}$ clamp [25] was conducted using a primed and continuous infusion of human recombinant insulin (Actrapid) at a rate of $6 \mathrm{mU} \mathrm{kg}^{-1} \mathrm{~min}^{-1}$ coupled with a variable infusion of $25 \%$ (wt/vol.) glucose to maintain blood glucose concentration at approximately $6 \mathrm{mmol} / \mathrm{l}$. Blood glucose was measured every 5 min using a glucometer (Accu-Check Performa). Plasma insulin concentration was determined at the end of the clamp by EIA assay (SpiBio, Montigny le Bretonneux, France).

In vivo insulin stimulation and insulin signalling in skeletal muscle Male Wistar rats, fasted for $7 \mathrm{~h}$ prior to the experiments, were anaesthetised with sodium pentobarbital (35 mg/kg i.p., Sanofi Santé Animale, Centravet) and chlorpromazine ( $5 \mathrm{mg} / \mathrm{kg}$ i.p., Largactil; Sanofi-Aventis). Body temperature was maintained at $37^{\circ} \mathrm{C}$ with a homeostatic blanket (Harvard apparatus, les Ullis, France). A tracheotomy (PE240; Phymep, Paris, France) was performed to facilitate breathing. A catheter (PE-20) was inserted into the left jugular vein for 4-HHE infusion. Rats were either infused with 4HHE $(10 \mathrm{mg} / \mathrm{kg}$ in $0.1 \mathrm{ml} \mathrm{DMSO}, n=5)$ or $0.1 \mathrm{ml}$ of DMSO as a control $(n=4)$. One hour after infusion, rats received an intravenous injection of either saline $(154 \mathrm{mmol} / \mathrm{l}$ $\mathrm{NaCl})$ or insulin $(0.75 \mathrm{U} / \mathrm{kg}$ body weight). Thirty minutes after insulin injection, rats were killed with an intravenous overdose of sodium pentobarbital $(120 \mathrm{mg} / \mathrm{kg})$, blood was collected by heart puncture into a heparinised syringe and gastrocnemius muscle was rapidly dissected out, blotted dry and snap-frozen in liquid nitrogen.

Plasma 4-HHE and 4-HNE measurement Five hundred microlitres of plasma were used to measure 4-HHE and 4HNE by GC-MS as previously described [26].

Cell culture Rat L6 muscle cells were obtained from the American Type Culture Collection (LC/GC, Molsheim, France) and grown as described previously [15]. Cells were starved of serum for $4 \mathrm{~h}$ before treatments, which were performed in serum-free Minimum Essential Medium Eagle Alpha Modification (Sigma-Aldrich, Saint Quentin Fallavier, France). Viability and cell death were determined by 3-(4,5dimethylthiazol-2-yl)-2,5-diphenyltetrazolium bromide (MTT) reduction (Cell Proliferation Kit I; Roche), lactate dehydrogenase release (In vitro toxicology assay kit; SigmaAldrich) and caspase 3 activity (Caspase 3 Assay Kit; Sigma-Aldrich). Mycoplasma contamination was regularly tested by PCR. 
Table 1 Demographic and clinical characteristics of participants

\begin{tabular}{lccr}
\hline Characteristic & Healthy individuals & Type 2 diabetes & $p$ value \\
\hline Sex, $n$ male/ $n$ female & $15 / 2$ & $14 / 1$ & 0.738 \\
Age, years & $51(41-57)$ & $66(55-74)$ & $<0.001$ \\
BMI, $\mathrm{kg} / \mathrm{m}^{2}$ & $23.9 \pm 2.9$ & $30.8 \pm 5.0$ & $<0.001$ \\
Fasting plasma glucose, $\mathrm{mmol} / \mathrm{l}$ & $5.1(4.6-5.4)$ & $9.4(7.5-12.7)$ & $<0.001$ \\
$\mathrm{HbA}_{1 \mathrm{c}}, \mathrm{mmol} / \mathrm{mol}$ & $34.4(33.3-36.6)$ & $70.5(60.7-77.0)$ & $<0.001$ \\
$\mathrm{HbA}_{1 \mathrm{c}}, \%$ & $5.3(5.2-5.5)$ & $8.6(7.7-9.2)$ & $<0.001$ \\
Systolic blood pressure, $\mathrm{mmHg}$ & $129 \pm 13$ & $131 \pm 21$ & 0.770 \\
Diastolic blood pressure, $\mathrm{mmHg}$ & $81 \pm 11$ & $72 \pm 11$ & 0.045 \\
Total cholesterol, mmol/1 & $5.81 \pm 1.65$ & $3.94 \pm 1.11$ & 0.012 \\
$\mathrm{HDL}-\mathrm{cholesterol}, \mathrm{mmol} / \mathrm{l}$ & $1.22 \pm 0.31$ & $0.88 \pm 0.25$ & 0.009 \\
Triacylglycerols, mmol/l & $1.19 \pm 0.60$ & $2.22 \pm 0.87$ & 0.003 \\
\hline
\end{tabular}

Values are presented as mean $\pm \mathrm{SD}$ or as median (interquartile range) if data were not normally distributed

Statistical significance was determined by Student's $t$ test or Mann-Whitney $U$ test. Categorical data (i.e. sex) were compared using Fisher's exact test. $p<0.05$ was considered significant
2-Deoxy-D- $\left[{ }^{3} \mathrm{H}\right]$ glucose uptake Cells were treated with 4-HHE and incubated for $20 \mathrm{~min}$ with $100 \mathrm{nmol} / \mathrm{l}$ insulin or $20 \mu \mathrm{mol} / \mathrm{l}$ cytochalasin B. Glucose uptake was initiated by the addition of 2-deoxy-D- $\left[{ }^{3} \mathrm{H}\right]$ glucose $(747 \mathrm{GBq} / \mathrm{mmol})$ to a final concentration of $0.1 \mathrm{mmol} / 1$ for $5 \mathrm{~min}$ at $37^{\circ} \mathrm{C}$. Uptake was terminated by three washes in ice-cold PBS and solubilisation in $0.1 \%$ (wt/vol.) SDS. Tritium was detected by liquid scintillation counting and results normalised by protein concentration measured using the Bradford assay. Non-specific uptake measured in presence of cytochalasin B was subtracted from each determination.

\section{Spectrophotometric 2,4-dinitrophenylhydrazine assay} Carbonyl groups on proteins were determined using 2,4dinitrophenylhydrazine (DNPH) as previously described [27]. Carbonyl content was determined from the absorbance at a wavelength of $370 \mathrm{~nm}$ using a molar absorption coefficient of 22,000 $1 \mathrm{~mol}^{-1} \mathrm{~cm}^{-1}$ and normalised to the protein concentration measured at $280 \mathrm{~nm}$.

Protein extraction, immunoprecipitation and immunoblotting After incubation with 4-HHE, cells were washed with PBS and proteins were extracted as described previously

Table 2 Characteristics of 15-week-old lean and obese ZDF rats

\begin{tabular}{lcc}
\hline Characteristic & Lean & \multicolumn{1}{l}{ Obese } \\
\hline Body weight, g & $385 \pm 7$ & $729 \pm 54 * * *$ \\
Fasting blood glucose, mmol/1 & $4.44 \pm 0.28$ & $25.50 \pm 1.33 * * *$ \\
Fasting insulin, pmol/1 & $168 \pm 26$ & $427 \pm 52^{* * *}$ \\
$\mathrm{HbA}_{1 \mathrm{c}}(\mathrm{mmol} / \mathrm{mol})$ & $28.3 \pm 1.7$ & $73.9 \pm 2.3 * * *$ \\
$\mathrm{HbA}_{1 \mathrm{c}}(\%)$ & $4.74 \pm 0.28$ & $8.91 \pm 0.28 * * *$ \\
\hline
\end{tabular}

Values are mean \pm SEM, $n=5$

$* * * p<0.001$ vs lean (Student's $t$ test)
[15]. For IRS1/p85 detection, whole-cell lysates were immunoprecipitated using antibodies against IRS1. Proteins were boiled in Laemmli buffer, separated by SDS-PAGE and transferred onto nitrocellulose membrane. For dot blotting, $20 \mu \mathrm{g}$ of proteins from whole-cell lysate were loaded directly onto the nitrocellulose membrane. Following saturation with $5 \%$ (wt/vol.) BSA, membranes were probed with antibodies and processed for chemiluminescence (ECL plus; GE Healthcare, Coutaboeuf, France). Quantification was performed using the ImageJ software (National Institutes of Health, Bethesda, USA).

Immunofluorescence L6 cells grown on coverslips were incubated with 4-HHE, fixed for $30 \mathrm{~min}$ with $3 \%$ (wt/vol.) paraformaldehyde and quenched with $50 \mathrm{mmol} / 1 \mathrm{NH}_{4} \mathrm{Cl}$ for $5 \mathrm{~min}$. After PBS washing, cells were permeabilised with $50 \mu \mathrm{g} / \mathrm{ml}$ digitonin for $10 \mathrm{~min}$ and blocked with $0.1 \%$ (wt/vol.) BSA for $30 \mathrm{~min}$. The cells were incubated with the first antibodies and then washed and labelled with fluorescent secondary antibodies. The stained cells mounted in Mowiol (Sigma Aldrich, Saint Quentin Fallavier, France) were examined under a Zeiss LSM 510 confocal microscope (Zeiss, Marly le Roy, France) equipped with $63 \mathrm{~W}$ oil objective and fluorescence was quantified using Image J software v1.56.

Glutathione assay Reduced glutathione (GSH) was measured using a commercially available kit from BioVision (Clinisciences, Montrouge, France) and normalised to the protein concentration measured using the Bradford assay.

Statistics Experimenters were not blind to group assignment. Data were analysed using Graphpad Prism (Graphpad Software, La Jolla, CA, USA) and presented as means \pm SEM. Results were compared by one-way or two-way ANOVA followed when appropriate by post hoc Fisher 
Fig. 1 Plasma levels of 4-HHE are increased in type 2 diabetes. (a) Concentration of 4-HHE and 4-HNE in plasma from individuals with type 2 diabetes or from healthy volunteers, measured using GC-MS. (b) 4HHE adducts on plasma proteins, measured by dot blot using anti-4HHE Michael adduct antibody. AU, arbitrary units. (c) Normalisation of 4-HHE and 4HNE to the concentration of $n-6$ PUFA and $n$ - 3 PUFA, respectively, measured by GC. (d) Correlation between plasma 4HHE levels and blood glucose levels. (e) Concentration of 4$\mathrm{HHE}$ and 4-HNE in plasma from obese ZDF rats $(n=5)$ or lean ZDF rats $(n=5)$, measured by GC-MS. (f) Blood glucose levels in the lean and obese ZDF rats measured using a glucometer.

Data are means or means \pm SEM. $* * * p<0.001$ (two-way

ANOVA). White circles, healthy volunteers (control); black squares, individuals with type 2 diabetes (T2D); white triangles, lean ZDF rats; black triangles, obese ZDF rats a

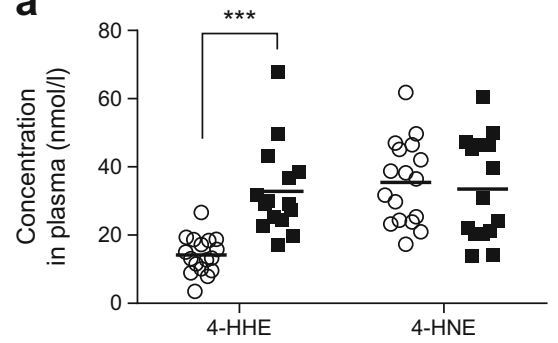

b

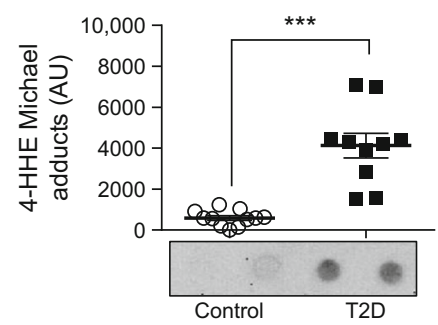

d
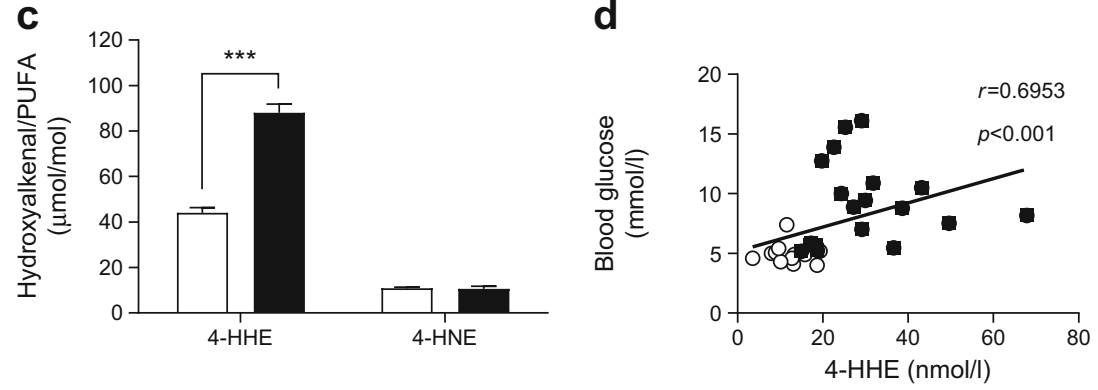

e

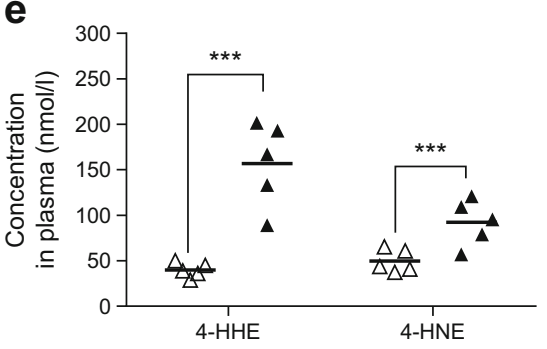

f

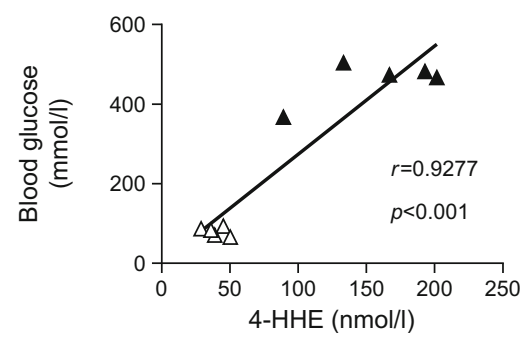

PLSD tests. Simple comparisons were performed with Student's $t$ test using Welch's correction for variance in homogeneity whenever needed. Differences were considered significant at the $p<0.05$ level.

\section{Results}

4-HHE accumulates in plasma from individuals with type 2 diabetes The concentration of free 4-HHE, measured using GC-MS, was significantly increased in plasma from individuals with type 2 diabetes compared with plasma from healthy volunteers (33 vs $14 \mathrm{nmol} / 1$, $p<0.001$ ) (Fig. 1a). Diabetic individuals also exhibited a significant increase (sevenfold) in 4-HHE Michael adducts on plasma proteins (Fig. 1b). In contrast, 4-HNE levels did not differ between diabetic and healthy individuals; neither did the plasma concentrations of $n-3$ and n-6 fatty acids (data not shown). Normalisation of 4HHE and 4-HNE to the concentration of their respective $n-3$ and $n-6$ precursors showed that one out of 20,000 n3 PUFA were oxidised in the form of 4-HHE, while only one out of 100,000 $n$-6 PUFA were oxidised in the form of 4-HNE (Fig. 1c). Significant correlations with 4-HHE plasma concentrations were found for blood glucose levels (Fig. 1d) and for $\mathrm{BMI}, \mathrm{HbA}_{1 \mathrm{c}}$, triacylglycerol and HDL-cholesterol (Table 3).

Table 3 Univariate correlations with 4-HHE plasma concentrations in participants

\begin{tabular}{lrr}
\hline Variable & $r$ & $p$ value \\
\hline Age, years & 0.420 & 0.017 \\
BMI, $\mathrm{kg} / \mathrm{m}^{2}$ & 0.692 & $<0.001$ \\
$\mathrm{SBP}, \mathrm{mmHg}$ & 0.014 & 0.942 \\
DBP, mmHg & -0.300 & 0.113 \\
Fasting glucose, mmol/1 & 0.695 & $<0.001$ \\
HbA $_{1 \mathrm{c}}$ (mmol/mol) & 0.750 & $<0.001$ \\
Triacylglycerol, mmol/1 & 0.588 & 0.003 \\
Total cholesterol, mmol/1 & -0.302 & 0.184 \\
HDL-cholesterol, mmol/1 & -0.549 & 0.007 \\
4-HNE, nmol/l & 0.267 & 0.139 \\
Total $n$-3 PUFA, mmol/l & 0.643 & $<0.001$ \\
4-HHE Michael adducts, AU & 0.805 & $<0.001$ \\
\hline
\end{tabular}

AU, arbitrary units; DBP, diastolic BP; SBP, systolic BP 
4-HHE and 4-HNE in plasma from ZDF rats A plasma concentration of $40 \mathrm{nmol} / \mathrm{l}$ of free $4-\mathrm{HHE}$ was measured in lean ZDF rats and a fourfold increase $(p<0.001)$ was observed in obese ZDF rats (Fig. 1e). The plasma concentration of 4-HNE was increased by $80 \%$ in ZDF rats $(p<0.001)$. As in humans, a significant correlation was found between the concentration of 4-HHE and blood glucose levels (Fig. 1f).

4-HHE infusion induces insulin resistance in rats To demonstrate that 4-HHE plays a causal role in insulin resistance, insulin sensitivity was measured using euglycaemichyperinsulinaemic clamps in Wistar rats given an intravenous bolus of 4-HHE $(10 \mathrm{mg} / \mathrm{kg})$. The injection induced a transient increase in plasma concentration of 4-HHE, which reached $140 \mathrm{nmol} / 130 \mathrm{~min}$ after injection, while plasma 4-HNE concentration remained unaffected (Fig. 2a). The clamp was applied at a blood glucose level of approximately $6 \mathrm{mmol} / \mathrm{l}$ (Fig.
$2 b, c)$. The glucose infusion rate necessary to maintain euglycaemia was significantly lower in the 4-HHE infused rats than in the DMSO-infused rats (Fig. 2d,e), indicating whole-body insulin resistance. In another set of experiments, rats were infused with 4 -HHE for $2 \mathrm{~h}$ and then received a single injection of insulin for $20 \mathrm{~min}$. Under these conditions, the infusion of 4-HHE prevented the decreased in blood glucose level induced by insulin (Fig. 2f) and abolished insulininduced phosphorylation of Akt in skeletal muscle (Fig. 2g,h).

Impaired insulin-stimulated glucose uptake in response to 4HHE In lean animals, 80-90\% of infused glucose is taken up by skeletal muscle [28] so the clamp technique primarily reflects skeletal muscle insulin sensitivity. We therefore went on to characterise 4-HHE-induced insulin resistance in skeletal muscle cells. In rat L6 cells, 4-HHE completely blunted insulin-induced 2-deoxy-D- $\left[{ }^{3} \mathrm{H}\right]$ glucose uptake (Fig. 3a), with a
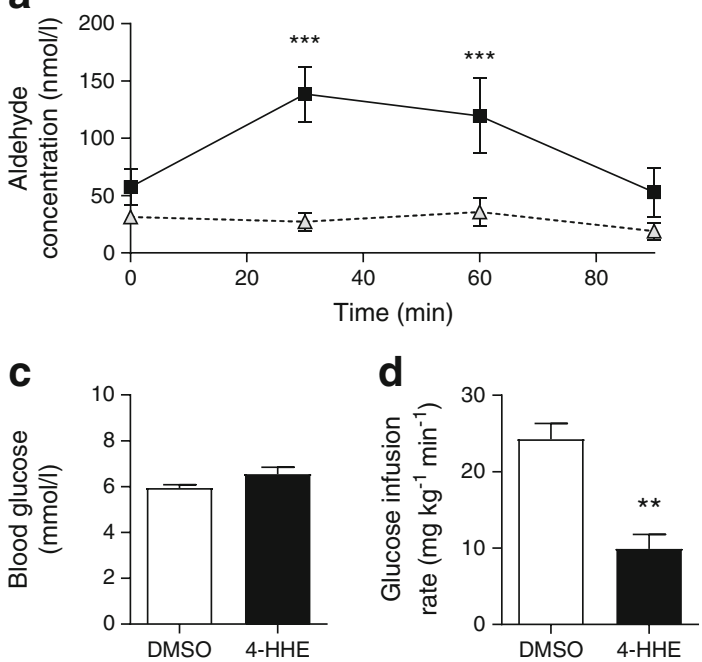

b
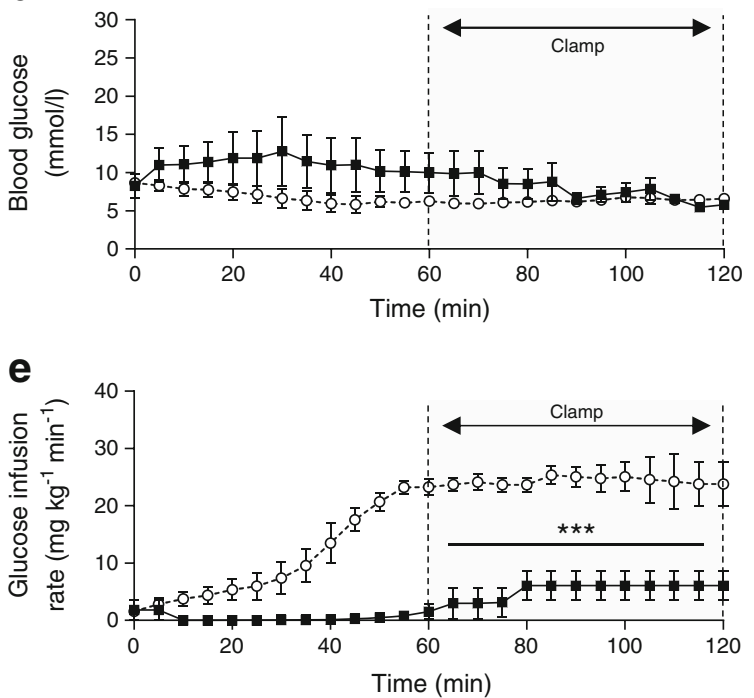

h

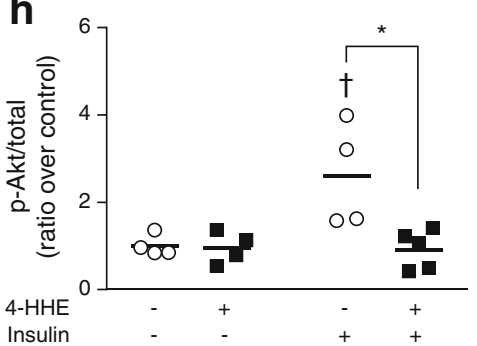

Fig. 2 4-HHE infusion induces insulin resistance in rats. Euglycaemic-hyperinsulinaemic clamps were performed in anaesthetised Wistar rats infused with 4-HHE (10 mg/kg i.v.) or vehicle (DMSO) as described in Methods. (a) 4-HHE (black squares) and 4-HNE (grey triangles) concentration in 4-HHE-infused rats, measured in plasma over the $2 \mathrm{~h}$ of the clamp experiment. Results are means \pm SEM, $n=4$. $* * * p<0.001$ vs time zero. (b) Blood glucose was monitored every 5 min using a glucometer and glucose infusion rate was adjusted accordingly. (c, d) Mean blood glucose (c) and glucose infusion rate (d) during the second hour of clamp. (e) In a separate experiment, rats were injected with 4-HHE $(n=5)$ or DMSO $(n=4)$ and after $2 \mathrm{~h}$ stimulated with insulin for $20 \mathrm{~min}$; during euglycaemic-hyperinsulinaemic clamp, glucose infusion rate was adjusted accordingly over $2 \mathrm{~h}$. (f) Blood glucose levels were measured with a glucometer. $(\mathbf{g}, \mathbf{h})$ Representative western blot $(\mathbf{g})$ and quantification (h) of insulin-induced phosphorylation of Akt following 4HHE and insulin injections. Data are means \pm SEM, $n=4 . * p<0.05$, $* * p<0.01$ and $* * * p<0.001$ for indicated comparisons or vs DMSO; ${ }^{\dagger} p<0.05$ vs no insulin $(\mathbf{d}-\mathbf{f}, \mathbf{h})$. Black squares and bars, rats infused with 4-HHE; white circles and bars, rats infused with DMSO control 
a

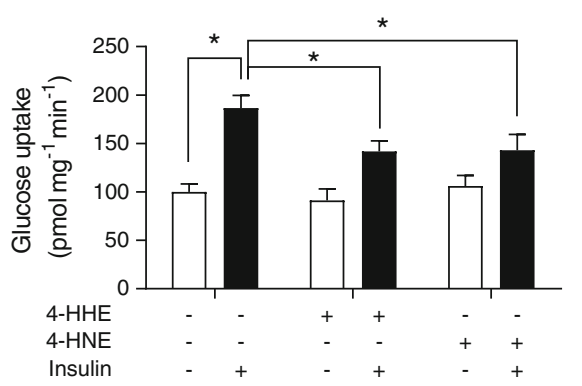

Fig. 3 4-HHE impairs insulin-induced glucose uptake. Rat L6 muscle cells were treated with 4-HHE or 4-HNE and then stimulated with $100 \mathrm{nmol} / \mathrm{l}$ insulin for $20 \mathrm{~min}$. 2-Deoxy-D- $\left[{ }^{3} \mathrm{H}\right]$ glucose uptake was measured as described in the Methods. (a) Glucose uptake in L6 muscle cells treated for $60 \mathrm{~min}$ with $50 \mu \mathrm{mol} / \mathrm{l}$ 4-HHE or 4-HNE. Data are means \pm SEM, $n=5$. $* p<0.05$ for indicated comparisons (two-way ANOVA b

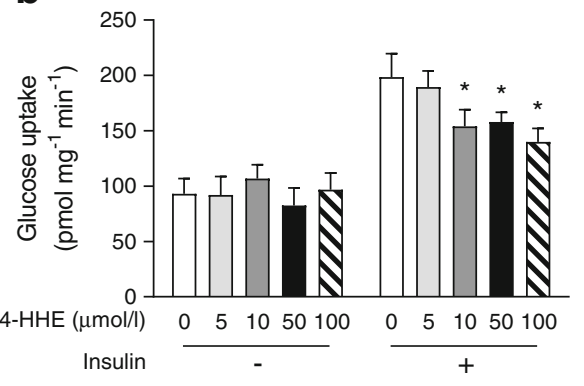

C

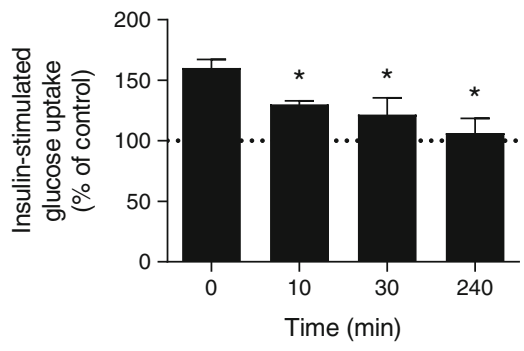

for insulin vs aldehydes). (b) Glucose uptake in L6 cells treated for 30 min with increasing concentrations of 4-HHE. Data are means \pm SEM, $n=5 . * p<0.05$ vs $0 \mu \mathrm{mol} / 14-\mathrm{HHE}+100 \mathrm{nmol} / 1$ insulin (twoway ANOVA). (c) Time course of insulin-stimulated glucose uptake in L6 cells in response to $10 \mu \mathrm{mol} / \mathrm{l}$ 4-HHE. Data are means \pm SEM, $n=5$. $* p<0.05$ vs 0 min (one-way ANOVA)

maximal inhibition observed starting at $10 \mu \mathrm{mol} / \mathrm{l}$ (Fig. 3b), lower than the concentration of 4-HNE previously reported to impair insulin response in adipocytes and muscle cells [14, 15]. Insulin-induced glucose uptake was similarly blunted in L6 cells exposed to 4-HNE, but with a maximal inhibition obtained at a concentration of $50 \mu \mathrm{mol} / \mathrm{l}$. Significant inhibition of insulin-induced glucose uptake by 4-HHE was observed from $10 \mathrm{~min}$ until $4 \mathrm{~h}$ of treatment (Fig. 3c). In cells treated for $30 \mathrm{~min}$ with up to $100 \mu \mathrm{mol} / \mathrm{l}$ 4-HHE, MTT reduction, lactate dehydrogenase (LDH) release and caspase- 3 activity remained unaffected, demonstrating no deleterious effects on cell viability at times and concentrations used (Table 4).
Impaired insulin signalling induced by 4-HHE in rat L6 muscle cells The insulin signalling cascade leading to glucose uptake can be affected at various stages: GLUT4 translocation; protein kinase B (PKB)/Akt and/or upstream at the insulin receptor and IRS. In response to 4-HHE or 4-HNE, insulin-induced phosphorylation of PKB/Akt was reduced by $50 \%$ (Fig. 4a). 4-HHE was effective at inhibiting insulin-induced Akt phosphorylation at concentrations ranging from 10 to $100 \mu \mathrm{mol} / 1$ (Fig. 4b). Similarly, exposure to 4-HHE significantly impaired insulin-induced IRS1 phosphorylation (Fig. 4c), in parallel with a marked reduction in the level of $\mathrm{p} 85$ protein coimmunoprecipitated with IRS1 (Fig. 4d).
Table 4 Effect of 4-HHE and 4-HNE on rat L6 muscle cell viability

\begin{tabular}{llll}
\hline $\begin{array}{l}\text { Aldehyde } \\
\text { concentration }\end{array}$ & $\begin{array}{l}\text { Cell viability } \\
(\% \text { of control })\end{array}$ & $\begin{array}{l}\text { LDH activity } \\
(\% \text { of total })\end{array}$ & $\begin{array}{l}\text { Caspase 3 activity } \\
\text { \% of control })\end{array}$ \\
\hline $4-\mathrm{HHE}$ & & & $116 \pm 2$ \\
$10 \mu \mathrm{mol} / 1$ & $108 \pm 2$ & $0.9 \pm 0.2$ & $117 \pm 6$ \\
$25 \mu \mathrm{mol} / 1$ & $101 \pm 3$ & $1.5 \pm 0.8$ & $116 \pm 12$ \\
$50 \mu \mathrm{mol} / 1$ & $107 \pm 4$ & $0.9 \pm 0.2$ & $119 \pm 14$ \\
$75 \mu \mathrm{mol} / 1$ & $120 \pm 5$ & $1.8 \pm 0.7$ & $121 \pm 12$ \\
$100 \mu \mathrm{mol} / 1$ & $125 \pm 1$ & $1.1 \pm 0.3$ & $115 \pm 16$ \\
$4-\mathrm{HNE}$ & $105 \pm 5$ & $2.1 \pm 0.4$ & $122 \pm 15$ \\
$10 \mu \mathrm{mol} / 1$ & $105 \pm 3$ & $2.6 \pm 0.6$ & $116 \pm 13$ \\
$25 \mu \mathrm{mol} / 1$ & $108 \pm 5$ & $2.4 \pm 0.9$ & $119 \pm 19$ \\
$50 \mu \mathrm{mol} / 1$ & $109 \pm 3$ & $2.4 \pm 0.9$ & $140 \pm 20$ \\
$75 \mu \mathrm{mol} / 1$ & $106 \pm 2$ & $4.1 \pm 1.3$ & \\
$100 \mu \mathrm{mol} / 1$ & & & \\
\hline
\end{tabular}

Data are means \pm SEM from four independent experiments

L6 muscle cells were treated for 30 min with increasing doses of 4-HHE or 4-HNE in serum-free conditions. Cell viability was measured by MTT assay and expressed as a percentage of untreated control. LDH activity in the supernatant fraction was expressed as a percentage of the maximal level of LDH activity determined after total cell lysis. Caspase-3 activity was expressed as a percentage of the specific activity present in vehicle-treated cells No significant effects were found 
Fig. 4 4-HHE impairs insulin signalling. Rat L6 cells were treated for $30 \mathrm{~min}$ with $50 \mu \mathrm{mol} / 1$ 4-HHE or 4-HNE and then stimulated with $100 \mathrm{nmol} / 1$ insulin for $20 \mathrm{~min}$. Protein extracts were analysed by western blotting. (a) Phosphorylation of Akt. (b) Phosphorylation of Akt in response to increasing concentrations of 4-HHE. (c) Tyrosine phosphorylation of IRS1. (d) p85 coimmunoprecipitated with IRS1. Data are expressed as means \pm SEM, $n=4 . * p<0.05$ for indicated comparison or vs insulin-stimulated cells untreated with 4-HHE (two-way ANOVA in $\mathbf{a}, \mathbf{c}$ and $\mathbf{d}$; one-way ANOVA in b) a

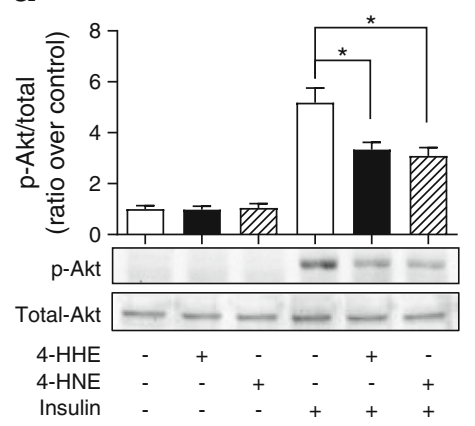

C

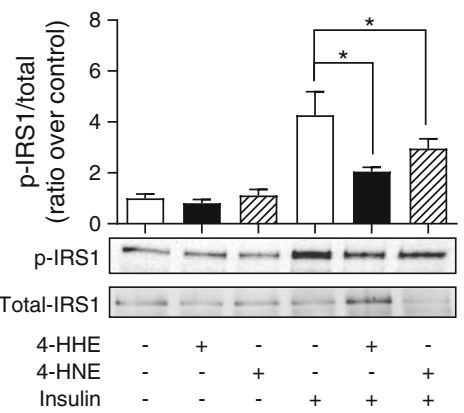

b

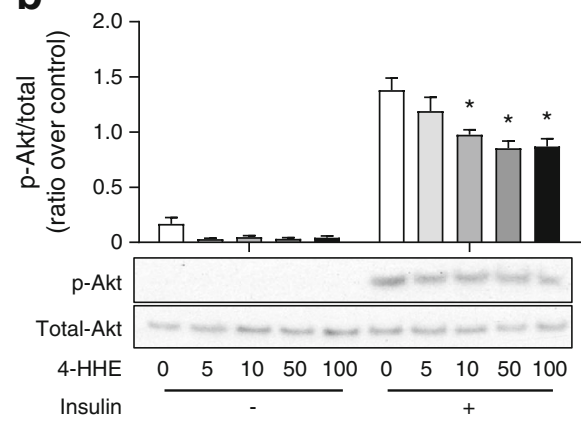

d

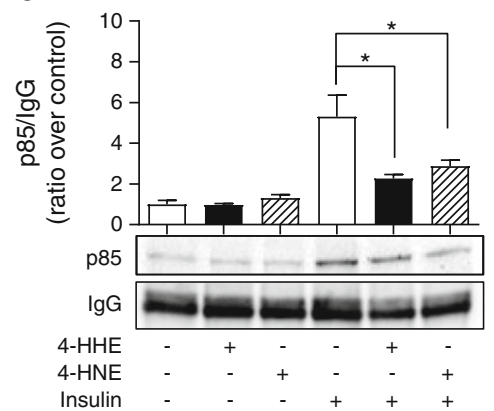

4-HHE generates protein adducts in rat L6 muscle cells Many deleterious effects of aldehydes have been attributed to their ability to form covalent adducts on biomolecules [5]. Indeed, incubation of L6 muscle cells for $30 \mathrm{~min}$ with 4-HHE resulted in a dose-dependent increase in carbonyl content (Fig. 5a) and increased formation of 4-HHE Michael adducts on proteins (Fig. 5b). Western blot analysis revealed the presence of 4 HHE adducts on many proteins from 30 to $100 \mathrm{kDa}$ (Fig. 5c) and confocal microscopy showed that the formation of adducts was diffuse in the cell cytoplasm but was excluded from the nuclei (Fig. 5d) without any specific co-localisation with actin cytoskeleton or the Golgi apparatus (data not shown). These data demonstrate that $10 \mu \mathrm{mol} / \mathrm{l} 4$-HHE is sufficient to induce carbonylation of cytoplasmic proteins in muscle cells.

Elevation of glutathione pools reverses 4-HHE-impaired glucose uptake Reduced glutathione (GSH) is one of the major aldehyde detoxification mechanisms [29]. Treatment with increasing concentrations of 4-HHE indeed resulted in a sharp dose-dependent decrease in GSH content in rat L6 muscle
Fig. 5 4-HHE-induced carbonylation in muscle cells. Rat L6 cells were exposed to 4-HHE for $30 \mathrm{~min}$. (a) Carbonylation of proteins, estimated using DNPH assay. Data are means $\pm \mathrm{SEM}, n=$ 3. (b, c) Adduct formation on proteins was determined by dot blot (b) and western blot (c) using antibodies against 4-HHE

Michael adducts. Data are means \pm SEM, $n=6$. Representative blots are shown. (d) Immunofluorescence was performed with confocal microscopy using antibodies to 4HHE adducts. Representative images from at least five different fields are shown. Scale bar, $10 \mu \mathrm{m} . * * * p<0.001$ vs no 4 HHE (one-way ANOVA). MW, molecular weight a

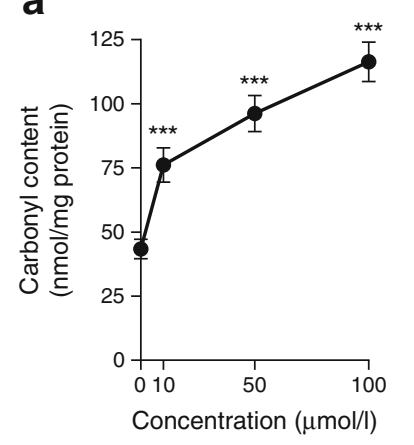

b

d

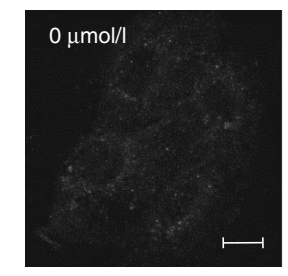

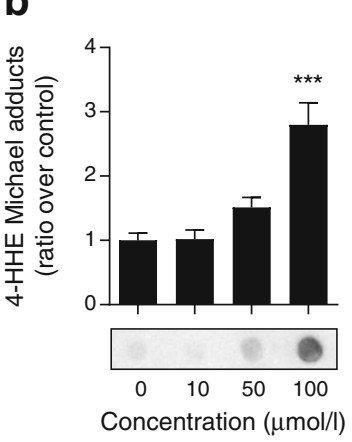

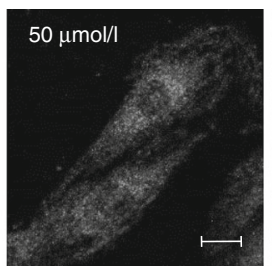

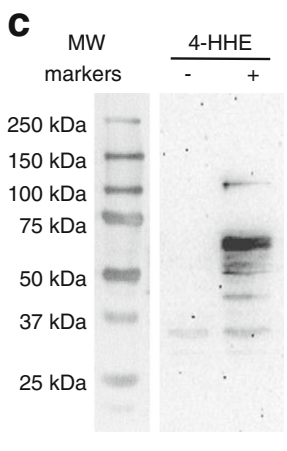

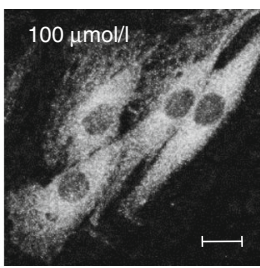



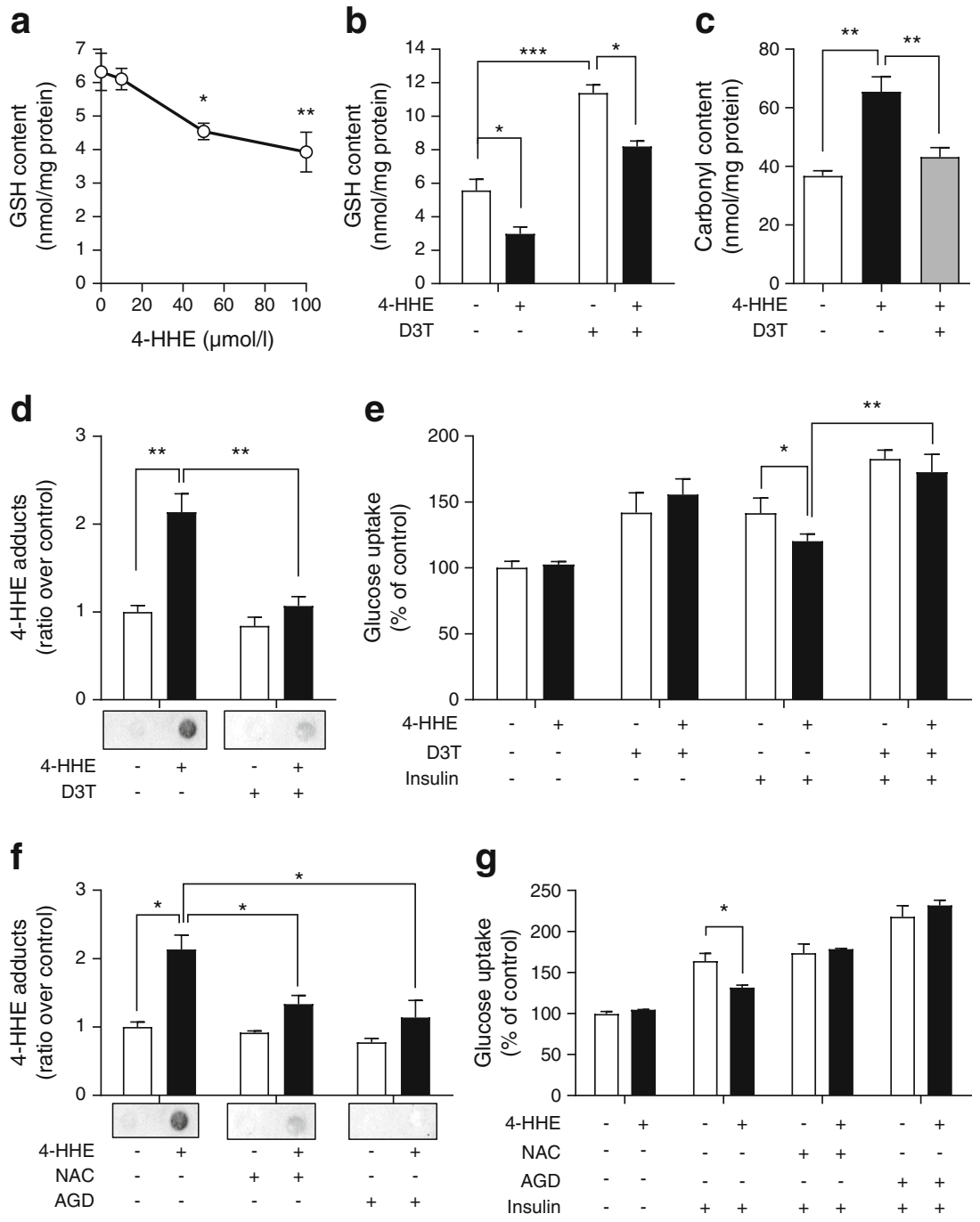

Fig. 6 Increasing glutathione levels reverses 4-HHE-induced adduct formation and impaired glucose uptake in muscle cells. (a) GSH was measured in rat L6 muscle cells using a commercially available kit. Data are means \pm SEM, $n=3$. (b) L6 cells were pre-incubated with $100 \mu \mathrm{mol} / 1$ of D3T for $24 \mathrm{~h}$ and then treated with $50 \mu \mathrm{mol} / 1$ 4-HHE for 30 min. GSH was measured as described in Methods. Data are means \pm SEM, $n=3$. (c) After D3T pre-incubation, L6 cells were exposed to $50 \mu \mathrm{mol} / 1 \mathrm{4}$-HHE for $30 \mathrm{~min}$. Carbonylation of proteins was assayed using the DNPH assay. Data are means \pm SEM, $n=4$. (d) Michael adducts on proteins were detected with a dot blot using antibodies to 4-HHE

cells (Fig. 6a). This decrease was reversed by pre-treatment with D3T $(100 \mu \mathrm{mol} / \mathrm{l}, 24 \mathrm{~h})$, which doubled the intracellular GSH content and counteracted the decrease induced by 4HHE (Fig. 6b). D3T also reversed the 4-HHE-induced increase in total carbonyl content (Fig. 6c) and protein adducts in the cells (Fig. 6d). Pre-treatment with D3T increased the basal glucose uptake and effectively prevented 4-HHEinduced insulin resistance (Fig. 6e). Similarly, pre-treatment of L6 muscle cells with $N$-acetyl-cysteine (NAC) or the scavenger of lipid peroxidation by-products aminoguanidine (AGD) also attenuated Michael adduct formation (Fig. 6f) and prevented the impaired insulin-induced glucose uptake

adducts. Data are means \pm SEM, $n=3$. (e) After D3T pre-incubation and 4-HHE exposure, insulin-stimulated glucose uptake was measured using 2-deoxy-D-[ $\left.{ }^{3} \mathrm{H}\right]$ glucose. Data are means $\pm \mathrm{SEM}, n=4$. (f, g) L6 cells were pre-incubated with $1 \mathrm{mmol} / 1 \mathrm{~N}$-acetyl-cysteine (NAC) or $5 \mathrm{mmol} / \mathrm{l}$ aminoguanidine (AGD) for $24 \mathrm{~h}$ and then treated with $50 \mu \mathrm{mol} / \mathrm{l} 4$ HHE for $30 \mathrm{~min}$. Adducts on proteins were detected by dot blot (f) and glucose uptake was measured using 2-deoxy-D- $\left[{ }^{3} \mathrm{H}\right]$ glucose (g). Data are means \pm SEM, $n=4$. $* p<0.05, * * p<0.01$, *** $p<0.001$ for indicated comparisons or vs no 4-HHE (one-way ANOVA in a, $\mathbf{c}$; two-way ANOVA in $\mathbf{b}, \mathbf{d}-\mathbf{g}$ )

(Fig. 6g) induced by 4-HHE. Altogether, these data confirm that adduct formation is a major player in 4-HHE-induced insulin resistance.

\section{Discussion}

Diabetes is associated with increased oxidative stress in metabolic tissues and excessive production of reactive oxygen species negatively affects insulin responses [2]. Oxidative stress can impair cell function through direct attack by reactive oxygen species and via the production of reactive oxidation 
by-products. Here, we demonstrate that one of the by-products of $n-3$ PUFA peroxidation, 4-HHE, is increased in plasma during type 2 diabetes, induces insulin resistance in vivo and impairs glucose uptake and signalling in skeletal muscle cells in vitro.

Unlike radical oxygen species, lipid peroxidation byproducts are long-lived and may spread from their site of production to exert their effects throughout the whole organism. Previous reports show that the plasma concentration of free 4-HNE ranges from $70-600 \mathrm{nmol} / 1$ at baseline to up to 2$10 \mu \mathrm{mol} / 1$ under pathological conditions [11, 30, 31]. In our study, the 4-HNE plasma concentration in healthy volunteers was $50 \mathrm{nmol} / 1$ and was surprisingly unchanged in individuals with type 2 diabetes. On the contrary, 4-HHE concentration was doubled in individuals with type 2 diabetes compared with healthy individuals. The measurement of free 4-HHE or 4-HNE by GC does not take into account the amount of aldehydes bound to biomolecules. There are no commercially available ELISA kits for 4-HHE adducts, so we used dot blots to demonstrate that plasma proteins from individuals with type 2 diabetes exhibit higher levels of 4-HHE Michael adducts (sevenfold increase). The accumulation of protein adducts (carbonyls) has been reported in individuals with type 2 diabetes; urinary levels of acrolein adducts are increased and significantly correlated with control of blood glucose [32]. A previous study has reported a fivefold increase in 4-HHE Michael adducts on phospholipids during diabetic retinopathy [33]. Our study therefore reinforces the evidence for increased production of aldehyde by-products and their adducted targets during diabetes.

Daily supplementation with $800-1600 \mathrm{mg}$ docosahexaenoic acid (DHA) in healthy volunteers significantly increased plasma free 4-HHE (from 9 to $93 \mathrm{nmol} / \mathrm{l}$ ), likely resulting from increased lipid peroxidation [34]. Interestingly, a DHA supplement that did not significantly increase plasma 4-HHE (400 mg DHA/day) had beneficial effects on platelet function and induced antioxidant effects [35], more recently confirmed in individuals with type 2 diabetes [36]. In human volunteers who take $n$-3 PUFA supplements, the balance between the beneficial effects of DHA supplementation and the potential deleterious effects of its by-products is therefore difficult to assess and might depend on the concentration of DHA as well as the oxidative environment.

Data from animal models and cell culture suggest that oxidative stress plays a causative role in the development of type 2 diabetes. Reactive oxygen species and their by-products can have a negative impact on insulin sensitivity [2] and we demonstrate here that $10 \mu \mathrm{mol} / 1 \mathrm{4}$-HHE is sufficient to impair insulin-induced glucose uptake. In rat L6 muscle cells, impaired glucose uptake likely results from an alteration of insulin-induced PKB/Akt phosphorylation on serine 473 as well as IRS1 tyrosine phosphorylation and p85 docking.
Insulin-induced IRS1 phosphorylation can be counteracted by serine phosphorylation conducted for instance by mitogen-activated protein kinase [37, 38]. However, extracellular signal-regulated kinase and c-Jun N-terminal kinases were only mildly activated by 4-HHE in L6 cells (data not shown), suggesting that these kinases do not play a major role in the impairment of insulin signalling in this context. On the contrary, we detected a significant accumulation of Michael adducts in L6 muscle cells exposed to 4-HHE, suggesting that the major effects of 4-HHE are due to protein carbonylation. Detoxification of aldehydes in cells is fulfilled by several enzymes and antioxidant systems. Compared with 4-HNE, 4HHE is a poor substrate for aldehyde dehydrogenase $5 \mathrm{~A}$ [39] but is metabolised to GSH adducts more efficiently [40], suggesting that GSH metabolism may be the major mechanism for detoxification of 4-HHE. In our study, prevention of carbonylation either by increasing glutathione pools with D3T or by using the by-product scavenger aminoguanidine reversed 4-HHE-induced insulin resistance. This favours the notion that 4-HHE impairs insulin signalling through the formation of covalent adducts on key proteins and that GSH is a major means by which to prevent its deleterious effects. In 3T3 adipocytes, 4-HNE directly binds IRS1 and promotes its degradation [14]; however, we did not observe any change in the total amount of PKB/Akt and IRS1 proteins in response to 4-HHE. It is therefore likely that 4-HHE exerts its noxious effects through adduction of proteins but not through the specific degradation of proteins of the insulin signalling pathway.

In conclusion, we demonstrate that plasma levels of 4-HHE are significantly increased in type 2 diabetes and that 4-HHE can significantly impede insulin action in vitro and in vivo. We also report that increasing the GSH pool is an efficient way to prevent 4-HHE-induced carbonylation of cellular proteins and impairment of insulin signalling. These data support the idea that lipid peroxidation by-products, especially 4-HHE, can significantly contribute to the development of type 2 diabetes and could represent a therapeutic target to taper insulin resistance.

Acknowledgements We gratefully acknowledge A. Geloën (CNRS, France) for fruitful discussions, R. Vella, A. Carravieri and Y.-H. Chionh (INSA-Lyon, France) for contributing to the experiments, A. Makino (INSA-Lyon, France) for advising on confocal microscopy, R. Colas (INSA-Lyon, France) for the kind gift of human plasma and P. Moulin and C. Pelletier (both from Hospices Civils de Lyon, France) for the selection of volunteers. Some of the data were presented as an abstract at the 53rd EASD Annual Meeting in 2017.

Data availability The data generated during and/or analysed during the current study are available from the corresponding author on reasonable request.

Funding This work was supported by Inserm (France), INSA-Lyon (France) and the O. E. och Edla Johanssons vetenskapliga stiftelse (Sweden). NJP was supported by fellowships from the French ministry 
of Research and a Marie Skłodowska-Curie Fellowship (H2020-MSCAIF-2015, 704978).

Duality of interest The authors declare that there is no duality of interest associated with this manuscript.

Contribution statement COS and NJP conceived and designed the study, performed experiments and statistical analysis. BZ and LSP performed experiments and analysed data. LS performed the chemical synthesis of 4-HHE and 4-HNE and the purity analysis. MG performed and analysed the GC-MS measurement of plasma 4-HHE and 4-HNE. ML made substantial contributions to the conception or design of the work. All authors have contributed to drafting and revising the work, approved the final version to be published and agreed to be accountable for all aspects of the work in ensuring that questions related to the accuracy or integrity of any part of the work are appropriately investigated and resolved.

Open Access This article is distributed under the terms of the Creative Commons Attribution 4.0 International License (http:// creativecommons.org/licenses/by/4.0/), which permits unrestricted use, distribution, and reproduction in any medium, provided you give appropriate credit to the original author(s) and the source, provide a link to the Creative Commons license, and indicate if changes were made.

\section{References}

1. Ceriello A, Motz E (2004) Is oxidative stress the pathogenic mechanism underlying insulin resistance, diabetes, and cardiovascular disease? The common soil hypothesis revisited. Arterioscler Thromb Vasc Biol 24:816-823

2. Bashan N, Kovsan J, Kachko I et al (2009) Positive and negative regulation of insulin signaling by reactive oxygen and nitrogen species. Physiol Rev 89:27-71

3. Evans JL, Goldfine ID, Maddux BA, Grodsky GM (2002) Oxidative stress and stress-activated signaling pathways: a unifying hypothesis of type 2 diabetes. Endocr Rev 23:599-622

4. Van Kuijk FJ, Holte LL, Dratz EA (1990) 4-Hydroxyhexenal: a lipid peroxidation product derived from oxidized docosahexaenoic acid. Biochim Biophys Acta 1043:116-118

5. Pillon NJ, Soulère L, Vella RE et al (2010) Quantitative structureactivity relationship for 4-hydroxy-2-alkenal induced cytotoxicity in L6 muscle cells. Chem Biol Interact 188:171-180

6. Pillon NJ, Soulage CO (2012) Lipid peroxidation by-products and the metabolic syndrome. In: Catala A (ed.) Lipid peroxidation. InTech https://doi.org/10.5772/46019

7. Negre-Salvayre A, Coatrieux C, Ingueneau C, Salvayre R (2008) Advanced lipid peroxidation end products in oxidative damage to proteins. Potential role in diseases and therapeutic prospects for the inhibitors. Br J Pharmacol 153:6-20

8. Cohen G, Riahi Y, Sunda V et al (2013) Signaling properties of 4hydroxyalkenals formed by lipid peroxidation in diabetes. Free Radic Biol Med 65:978-987

9. Vistoli G, De Maddis D, Cipak A et al (2013) Advanced glycoxidation and lipoxidation end products (AGEs and ALEs): an overview of their mechanisms of formation. Free Radic Res 47(Suppl 1):3-27

10. Ihara Y, Toyokuni S, Uchida K et al (1999) Hyperglycemia causes oxidative stress in pancreatic beta-cells of GK rats, a model of type 2 diabetes. Diabetes 48:927-932

11. Traverso N, Menini S, Odetti P et al (2002) Diabetes impairs the enzymatic disposal of 4-hydroxynonenal in rat liver. Free Radic Biol Med 32:350-359
12. Traverso N, Menini S, Cosso L et al (1998) Immunological evidence for increased oxidative stress in diabetic rats. Diabetologia 41:265-270

13. Miwa I, Ichimura N, Sugiura M et al (2000) Inhibition of glucoseinduced insulin secretion by 4-hydroxy-2-nonenal and other lipid peroxidation products. Endocrinology 141:2767-2772

14. Demozay D, Mas J-C, Rocchi S, Van Obberghen E (2008) FALDH reverses the deleterious action of oxidative stress induced by lipid peroxidation product 4-hydroxynonenal on insulin signaling in 3T3-L1 adipocytes. Diabetes 57:1216-1226

15. Pillon NJ, Croze ML, Vella RE et al (2012) The lipid peroxidation by-product 4-hydroxy-2-nonenal (4-HNE) induces insulin resistance in skeletal muscle through both carbonyl and oxidative stress. Endocrinology 153:2099-2111

16. Gil A, Gil F (2015) Fish, a Mediterranean source of n-3 PUFA: benefits do not justify limiting consumption. Br J Nutr 113(Suppl 2):S58-S67

17. Awada M, Soulage CO, Meynier A et al (2012) Dietary oxidized n3 PUFA induce oxidative stress and inflammation: role of intestinal absorption of 4-HHE and reactivity in intestinal cells. J Lipid Res 53:2069-2080

18. Shibata N, Yamada S, Uchida K et al (2004) Accumulation of protein-bound 4-hydroxy-2-hexenal in spinal cords from patients with sporadic amyotrophic lateral sclerosis. Brain Res 1019:170 177

19. Yamada S, Funada T, Shibata N et al (2004) Protein-bound 4hydroxy-2-hexenal as a marker of oxidized n-3 polyunsaturated fatty acids. J Lipid Res 45:626-634

20. Tanito M, Elliott MH, Kotake Y, Anderson RE (2005) Protein modifications by 4-hydroxynonenal and 4-hydroxyhexenal in light-exposed rat retina. Invest Ophthalmol Vis Sci 46:38593868

21. Bacot S, Bernoud-Hubac N, Baddas N et al (2003) Covalent binding of hydroxy-alkenals 4-HDDE, 4-HHE, and 4-HNE to ethanolamine phospholipid subclasses. J Lipid Res 44:917-926

22. Je JH, Lee JY, Jung KJ et al (2004) NF-KB activation mechanism of 4-hydroxyhexenal via NIK/IKK and p38 MAPK pathway. FEBS Lett 566:183-189

23. Lee JY, Je JH, Jung KJ et al (2004) Induction of endothelial iNOS by 4-hydroxyhexenal through NF-kB activation. Free Radic Biol Med 37:539-548

24. Soulère L, Queneau Y, Doutheau A (2007) An expeditious synthesis of 4-hydroxy-2E-nonenal (4-HNE), its dimethyl acetal and of related compounds. Chem Phys Lipids 150:239-243

25. Kraegen EW, James DE, Bennett SP, Chisholm DJ (1983) In vivo insulin sensitivity in the rat determined by euglycemic clamp. Am J Phys 245:E1-E7

26. Michalski M-C, Calzada C, Makino A et al (2008) Oxidation products of polyunsaturated fatty acids in infant formulas compared to human milk-a preliminary study. Mol Nutr Food Res 52:14781485

27. Levine RL, Wehr N, Williams JA et al (2000) Determination of carbonyl groups in oxidized proteins. Methods Mol Biol 99:1524

28. Ferrannini E, Simonson DC, Katz LD et al (1988) The disposal of an oral glucose load in patients with non-insulin-dependent diabetes. Metab Clin Exp 37:79-85

29. Singhal SS, Singh SP, Singhal P et al (2015) Antioxidant role of glutathione S-transferases: 4-hydroxynonenal, a key molecule in stress-mediated signaling. Toxicol Appl Pharmacol 289:361370

30. Niki E (2009) Lipid peroxidation: physiological levels and dual biological effects. Free Radic Biol Med 47:469-484

31. Syslová K, Kacer P, Kuzma M et al (2009) Rapid and easy method for monitoring oxidative stress markers in body fluids of patients 
with asbestos or silica-induced lung diseases. J Chromatogr B Anal Technol Biomed Life Sci 877:2477-2486

32. Daimon M, Sugiyama K, Kameda W et al (2003) Increased urinary levels of pentosidine, pyrraline and acrolein adduct in type 2 diabetes. Endocr J 50:61-67

33. Bacot S, Bernoud-Hubac N, Chantegrel B et al (2007) Evidence for in situ ethanolamine phospholipid adducts with hydroxy-alkenals. J Lipid Res 48:816-825

34. Calzada C, Colas R, Guillot N et al (2010) Subgram daily supplementation with docosahexaenoic acid protects low-density lipoproteins from oxidation in healthy men. Atherosclerosis 208:467-472

35. Guillot N, Caillet E, Laville M et al (2009) Increasing intakes of the long-chain omega-3 docosahexaenoic acid: effects on platelet functions and redox status in healthy men. FASEB J 23:2909-2916

36. Véricel E, Colas R, Calzada C et al (2015) Moderate oral supplementation with docosahexaenoic acid improves platelet function and oxidative stress in type 2 diabetic patients. Thromb Haemost 114:289-296

37. Copps KD, White MF (2012) Regulation of insulin sensitivity by serine/threonine phosphorylation of insulin receptor substrate proteins IRS1 and IRS2. Diabetologia 55:2565-2582

38. Leonarduzzi G, Robbesyn F, Poli G (2004) Signaling kinases modulated by 4-hydroxynonenal. Free Radic Biol Med 37:1694-1702

39. Long EK, Murphy TC, Leiphon LJ et al (2008) Trans-4-hydroxy-2hexenal is a neurotoxic product of docosahexaenoic $(22: 6 ; n-3)$ acid oxidation. J Neurochem 105:714-724

40. Long EK, Rosenberger TA, Picklo MJ (2010) Ethanol withdrawal increases glutathione adducts of 4-hydroxy-2-hexenal but not 4hydroxyl-2-nonenal in the rat cerebral cortex. Free Radic Biol Med 48:384-390 